\title{
Um entre a ética e o reconhecimento
}

\section{Thiago Siqueira Venanzoni}

Doutorando do Programa de Pós-Graduação em Meios e Processos Audiovisuais (PPGMPA) da Escola de Comunicações e Artes da Universidade de São Paulo (ECA-USP), com bolsa Capes. Membro do MidiAto - Grupo de Estudos da Linguagem: Práticas Midiáticas. E-mail: thiagovenanzoni@usp.br
Resumo: As análises acadêmicas e não acadêmicas dos produtos audiovisuais buscam tensionar relações postas pelos objetos de formas diversas, e muitas delas se ocupam de uma crítica aos lugares estáveis construídos por percepções condicionadas pelas políticas estabelecidas e pelo que se faz como hegemonia na cena social. Entretanto, ao aproximar certas balizas teóricas na presença da mediação como um dispositivo ético, nota-se a necessidade e, não obstante, o apagamento de uma mesma questão: a noção de reconhecimento. $\mathrm{O}$ artigo tem como proposta aproximar os conceitos de ética, moral e reconhecimento como plataforma crítica para as análises dos objetos do campo do audiovisual por meio de contribuições trazidas por Serelle, Fraser e Safatle.

Palavras-chave: Ética; Reconhecimento; Crítica; Imagem; Cultura Audiovisual.

\section{One between ethics and recognition}

Abstract: Academic and non-academic analyses of media and audiovisual products seek many ways to strain objects' relations, many of them are critics to built establishment of perceptions that are conditioned by instituted and hegemonic policies in social scene. However, while approaching both theoretical beacons and mediation as an ethical device, we noted the need and deletion of a question: the notion of recognition. This paper proposes to approximate concepts of ethics, moral and recognition as a critic platform for objects' analyses in the audiovisual field through contributions made by Serelle, Fraser, and Safatle.

Keywords: Ethics; Recognition; Criticism; Image; Audiovisual Culture. 


\section{Mediação e reconhecimento}

Ao se tratar das análises de produtos audiovisuais, sejam quais forem esses objetos em discussão, temos a condição posta preliminarmente de que tratamos, antes de tudo, de mediação. E a implicação consequente dessa condição é a ética disposta não apenas no produto em análise mas - e o que este texto postula como debate - as próprias análises como parte importante na ética da mediação. O que se percebe, em alguma medida, são problematizações que levam os objetos ao debate da alteridade, de representações do outro, e formas dessas representações na mídia, nos produtos audiovisuais, mas que buscam trabalhálas em torno de uma abstração que, em muitas situações, se ausenta da política, das formas de vida das imagens, dos discursos que localizam esses objetos e como fazem efeito no real. Não temos como intenção equacionar o debate a partir deste texto, ao contrário, buscamos com ele abrir questões em torno de um lugar já compreendido das análises audiovisuais e da crítica, parte entendida a partir de enunciações estruturais, históricas e das narrativas em torno dos processos audiovisuais.

Um dos pontos se encontra na relação entre os modos de presença do audiovisual e a vida dos receptores e espectadores. Não seria demasiado relembrar como os aspectos tecnológicos, midiáticos e comunicacionais inferem decisivamente na vida cotidiana, na contemporaneidade das telas e das imagens. A mediação da tela se estabelece em afetos de toda ordem, em circuito participativo com a presença dela, mesmo quando a tecnologia é quase arcaica na sua condição de presença. Diante desse emblema contemporâneo, com raízes históricas, ascende novamente o debate sobre a mediação.

Trazendo de Roger Silverstone e Jesús Martín-Barbero partes do conceito, Serelle (2016) oferece à mediação um estatuto de complexidade em torno da cotidianidade, sendo esse lugar onde os modos de vida se dão. Ao não haver mais uma vida que esteja fora dos processos e narrativas midiáticas, das imagens em profusão, a mediação seria, antes de tudo, nessa concepção, algo elevado à tecnologia, aos meios maquínicos, às imagens técnicas,

pois depende cada vez mais da presença dos meios de comunicação no cotidiano, que colocam em circulação textualidades diversas, das quais nos apropriamos como recurso simbólico para estabelecer nossa conduta com o outro e para produzir sentidos na complexidade da vida cotidiana. Mas ela é também fundamentalmente social, pois implica a constante negociação cultural por meio de táticas do cotidiano (Ibid.: 76).

Formas cotidianas que dão vida ao que se reproduz na presença dos meios de comunicação e as reproduções que dão vida aos contratos culturais e às táticas do cotidiano. A todo instante se encontra a posição de vida ante a mediação. O desafio, transcreve Serelle em sua leitura, se faz, portanto, na análise como condição implicada à mediação, e que leva em consideração alguns aspectos históricos, tecnológicos e, sobretudo, "formas de circulação de significado" (Ibid.: 76). A análise seria, ao modo que o autor traz, uma forma crítica em relação ao objeto que se ocuparia de um comprometimento ético diante do social. E, ao assumir uma posição política - entendida em sua gramática expandida - em relação ao objeto em causa, assume-se também uma responsabilidade em torno da mediação. Em outros termos, as análises dos objetos audiovisuais se resumem a um conjunto de interrogações que possibilitariam construir ferramentas capazes de pôr em conflito as posições de vida em torno dessa mediação.

Um dos aspectos debatidos por Serelle em seu texto trazido a este artigo é o de lacunas da mediação e como, de algum modo, estamos implicados e somos responsáveis por elas. Aproxima-se ao que Silverstone traça como um paradigma 
crítico em torno da mediação, a "que resulta na aniquilação das diferenças e da qual somos cúmplices ou conluiados" (Ibid.: 77). Ao aniquilar a diferença como forma fundante da sociabilidade, havendo apenas identidades ou, para recuperarmos criticamente um termo em operação em vários estudos, representações, sociais e mediadas, o crítico também se coloca como cúmplice do que poderíamos nomear como hegemônico na cena social. Ao passo que Serelle, apoiado em Silverstone, credita à multiplicidade ou diversidade fator fundante na mediação do comum, das sociabilidades e dos vários sujeitos em causa. Esse seria o ponto central a ser discutido, localizar esse traço ético do analista ou crítico por meio do conceito de reconhecimento. Ou seja, mais do que identidade ou representação - que nos aparentam conceitos em conluio com as visibilidades encenadas por um Eu aniquilador das diferenças, que se coloca em lado oposto ao coletivo-, pensar em um reconhecimento como um lugar político.

Outro pronto trazido por Serelle em torno do conceito de mediação se dá na crítica por ele apresentada ao apostar na neutralidade dos meios. São impasses tensionados, sobretudo, pelo registro do acontecimento e da factualidade, como identifica o autor, na recorrência jornalística do registro do fato. Podemos acrescentar $a$ isso a reflexão nesse exercício proposto e imediatamente compreender que certos afastamentos no papel ilusório do crítico ou analista aposta, igualmente, no lugar de não mediação ou neutralidade. O que concorre ao saber científico do dado factual e da formalização metodológica da verdade dos fatos, aquela que se ausenta de menção explicita ao tecer crítico, sendo que esse se faz também acomodado em ideologias. Nesse último caso, ocasionando uma inversão clara da tradição crítica como uma contra-hegemonia, ou seja, aquilo que se coloca como crítica às ideologias.

Williams (2007) afirma haver um uso recorrente de mediação, que a descreve como processo essencial da ideologia e acaba por opor relações mediadas a reais, sendo que aquelas querem se passar por estas. Conciliado ao uso moderno de mídia como meio de comunicação de massa, essa acepção leva à noção de "que certas agências sociais estão deliberadamente interpostas entre a realidade e a consciência social para impedir a compreensão da realidade" (SERELLE, 2016: 78).

Portanto, a crítica como uma interferência nas formas hegemônicas de mediação equilibraria o cenário trazido por Raymond Williams. Ao deslocar o lugar crítico do saber científico e entendê-lo como partilha em uma "multiplicidade da mediação" (Ibid.: 79) aproximamos as ações concretas ao político, compreendendo-as como formas discursivas e se afastando da ideia de verdade. Isso também se aproxima do que Serelle marca como "gramática do reconhecimento" (Ibid.: 79). Diz o autor, a gramática explícita das mediações depende "de muitas variáveis, do gosto aos saberes adquiridos" (Ibid.: 79). Portanto, o modo como os sujeitos se colocam em relação ao objeto, em sua escolha, e com a sua percepção, lhe atribui valor, usos, e passaria por uma questão subjetiva, porém, não essencialista. Ou seja, é uma subjetividade em formação articulada constantemente com as mediações sociais. Assim, o papel da crítica, como buscamos por definição, não pode desprezar tais imbricações ao elucidar um produto audiovisual ou midiático, não deve se ausentar da gramática do reconhecimento, como propõem Serelle, e deve se responsabilizar por essa mediação ao interlocutor. Criando uma ponte com Jesús Martín-Barbero, é a afirmação de que um texto-e podemos nos reapropriar e dizer -, as imagens, as formas audiovisuais, não estão distantes do campo da cultura, ou seja, não existe uma verdade que opere sem os saberes discursivizados. No fazer crítico afirma-se necessário considerar em disputa os acirramentos ideológicos e localizar no reconhecimento os nós significantes no campo social.

Um ponto importante está em perceber que nesse lugar da cena social, e suas mediações enunciadas e negociadas, há sempre uma disputa. Se pensarmos como 


\begin{abstract}
${ }^{1}$ Michel Foucault vai desenvolver melhor esse pensamento em torno da resistência em seus últimos escritos e conferências. A dimensão ética e política desses modos de ser no coletivo e a hegemonia individual do governo de si em um contemporâneo que se fazia naquele instante. Em várias passagens, a afirmação passará a ser em torno das hegemonias e suas contravenções, em textos de identificação do poder, uma fase que percorre os escritos e ditos de Foucault dos anos de 1970. Em alguns desses textos também poderá ser notada uma crença de Foucault por um poder que operacionaliza o próprio poder de subjetivar os sujeitos. Ou seja, a individualidade de cada um, que autoriza a obrigação da identidade, é um sintoma efetivo do poder e uma conduta frequente no embate social. Seria, em si, uma forma de poder que desarticula o coletivo, um poder sobre o poder de si. Cf. Foucault (2012).
\end{abstract}

Foucault certa vez pensou e nos mostrou, o poder traz consigo sempre a resistência a ele ${ }^{1}$. É algo bastante próximo ao que Serelle apresenta à luz de Silverstone sobre a mediação ser assimétrica. Ou seja, não há uma posição fundante da gênese da mediação. Ao invés de apenas simetrias, ela apresenta também dissonâncias, confrontações. Localizam-se, portanto, velhas classificações, porém ainda fundamentais, como as noções de classe na estrutura social e de posições de sujeito. É igualmente um retorno ao reconhecimento como forma difusa, indivisível e, eminentemente, política. Diz Serelle sobre essa assimetria da mediação:

Ao mesmo tempo que enfatiza a dimensão cultural do fenômeno, sua imprevisibilidade e dinamicidade na circulação social de significados, Silverstone marca, também, a desigualdade do processo. O modo como determinada sociedade se engaja no uso e na confrontação dos "significados dominantes" não seria o mesmo em todas as classes, e tampouco as possibilidades são idênticas em sociedades que, por exemplo, experimentaram diferentes desenvolvimentos em serviços midiáticos públicos e comerciais, como os dos sistemas televisivos. A mediação é conflitiva, mas, assim como Williams, Silverstone reconhecia as pressões e o poder das instituições midiáticas estabelecidas para conformar usos da tecnologia, narrativas e esquemas representativos (SERELLE, 2016: 80).

O que está em jogo, mais uma vez, é a crítica como função social e política. A presença crítica deve se encontrar no "inesperado da mediação" (Ibid.: 81), aquilo que não se espera notar, e que, ao mesmo tempo, possibilite presenciar o local do poder e quais as suas significações, os seus modos de produção e de constituição vital. Nunca é demais remontar a posição de vida ante a mediação e a responsabilidade da crítica nesses modos de apropriação do outro, do que se apresenta em projeção.

Logo, ao tratar de vida e mediação, é preciso ter em questão a ética implicada nesses processos, ou, como faremos, tentar pensar as duas coisas em conjunto e realçar a pergunta feita por Nancy Fraser (2007): reconhecimento sem ética? Mais à frente vamos problematizar com maior acuidade o que se postula em Fraser e, junto a ela, reverter a questão. Porém, neste momento, interessa-nos determinar o que seria esse reconhecimento participante da ética da mediação, da qual as análises também localizam os efeitos.

Há em torno das teorias do reconhecimento e da tradição da crítica, a qual Fraser é uma participante bastante ativa, um longo debate calcado em temas bastante contemporâneos como identidade, redistribuição, ética, moral, que está no centro do que se conceitua reconhecimento ou lógica do reconhecimento. Nesse debate há um longo percurso histórico impossível de saldar em um artigo ou em uma abertura apenas. Dessa forma, iremos adotar aqui a noção do conceito de reconhecimento em Fraser sem, evidentemente, nos ausentar do debate. Assim, poderia ser formulada uma pergunta mediante o posto por Serelle: se a mediação é múltipla, assimétrica, diversa, como sustentar paridade na participação desses vários modos e como adotar um conceito de reconhecimento adequado à paridade?

A começar por uma condição de existência filosófica, que Fraser remonta como princípio ao comentar tais teorias, poderíamos dizer que há duas correntes em desalinho que necessitam de uma pactuação: uma é a redistribuição e a outra é o reconhecimento, propriamente. A primeira tem como meta a divisão mais igualitária do dinheiro em circulação, um debate que adentra o conflito distributivo das nações, a retirada dos ricos para os pobres por meios estatais, dos proprietários aos trabalhadores em espaço privado, resumidamente; enquanto a segunda cadeia significante busca traduzir os embates sociais e étnicos das diferentes minorias não visibilizadas na cena social, advindos, sobretudo, da segunda metade do século $X X$ aos dias de hoje. Fraser comenta que os dois campos pertencem a linhagens distintas, havendo aí um ponto fundante para que haja esse desalinho entre eles. 
A questão de fundo, e que nos parece a mais importante nessa disputa de sentido, é qual política adotar, a identificada como política social ou a reconhecida política identitária. Há farpas trocadas de todos os lados, com um lado acusando o outro de ser alinhado ao neoliberalismo, por vezes estereotipado como pósmoderno, enquanto o lado oposto, do reconhecimento, justifica sua contrariedade localizando um certo arcaísmo na utopia redistributiva, e que a desigualdade estaria em outros debates no contemporâneo. Adotamos um pensamento fraseriano, presente não apenas no texto aqui trabalhado, mas em toda articulação filosófica dela, que visa aproximações entre as duas políticas, já que

justiça, hoje, requer tanto redistribuição quanto reconhecimento; nenhum deles, sozinho, é suficiente. [...] A tarefa, em parte, é elaborar um conceito amplo de justiça que consiga acomodar tanto as reivindicações defensáveis de igualdade social quanto as reivindicações defensáveis de reconhecimento da diferença (FRASER, 2007: 103).

Ao mesmo tempo, a filósofa reconhece a dificuldade epistemológica em justificar essa reconciliação, e a entende como uma incompatibilidade entre duas filiações conceituais distintas que estão em disputa o tempo todo, a ver: o conceito de moral e o de ética. Não nos parece indicado, ao que se pretende pôr em discussão neste texto, entrar em todas as imbricações circundadas ao debate de Fraser, porém, há algo que atravessa o tempo todo as suas inquietações e que carece de uma acuidade maior de nossa parte. Foi citado anteriormente o que Serelle conceitua como multiplicidade, que difere de cumplicidade e aniquilação das diferenças. Há, dentro da vinculação do conceito de reconhecimento, a ideia de que a identidade é o primado, o que deve estar implicado nos laços de reconhecimento do outro. Antes, porém, retornemos ao ponto central trazido por Fraser em seu texto. Nele, há uma associação bastante explícita, dentro de cada uma das filiações conceituais de justiça de redistribuição e justiça do reconhecimento, aos conceitos de moral e ética; sendo a primeira própria à política da redistribuição, ou seja, como uma condição do direito, e a segunda pertencente a uma política do reconhecimento. O que se pretende nessa apreciação filiativa é, de fato, embaralhar esses pressupostos teóricos. O que recai sobre a ideia consagrada de identidade em torno da ética. Em outros termos, a ampliação de uma gramática do reconhecimento requer um questionamento crítico do conceito de identidade.

O modelo da identidade é profundamente problemático. Entendendo o não reconhecimento como um dano à identidade, ele enfatiza a estrutura psíquica em detrimento das instituições sociais e da interação social. Assim, ele arrisca substituir a mudança social por formas intrusas de engenharia da consciência. O modelo agrava esses riscos, ao posicionar a identidade de grupo como o objeto do reconhecimento. Enfatizando a elaboração e a manifestação de uma identidade coletiva autêntica, auto-afirmativa e auto-poiética, ele submete os membros individuais a uma pressão moral afim de se conformarem à cultura do grupo (FRASER, 2007: 106, grifos da autora).

Esse modelo, portanto, ainda que seja a forma mais presente em contrariedade ao não reconhecimento, esconde em si a sua incapacidade de evidenciar as diferenças. Parece um contrassenso, mas, ao que considera Fraser, é prática de um modelo. $\mathrm{Na}$ identidade não há a multiplicidade. A autora então propõe outras bases metodológicas para chegar à multiplicidade da mediação reivindicada por Serelle. O ponto que ela oferece é o de entender reconhecimento como status social. Isso levaria do espaço identitário ao espaço complexo da coletividade, ou, "o que exige reconhecimento não é a identidade específica de um grupo, mas a condição dos membros do grupo como parceiros integrais na interação social" (Ibid.: 107). Assim, a partir de um modelo que substitua a política de identidade por uma política do reconhecimento, faz-se produzir imaginário para uma inferência 
no plano moral. Desse modo, traduzir o reconhecimento seria distinto de falar em um desvio de identidade, o colocando sem reconhecimento, sem identidade de grupo. Ele também passa a ser reconhecido e ter significado, "uma subordinação social no sentido de ser privado de participar como um igual na vida social" (Ibid.: 107). No caso da crítica aos objetos audiovisuais, isso se torna flagrante em vários momentos, desde em valorizar determinadas características apresentadas em uma narrativa na construção do outro, positivando modos de estar socialmente em detrimento de diversas maneiras de existir no espaço social, até em formas de análise que desconhecem potências na fabricação do imaginário sobre o outro. Ambas incorrem sobre o modo identitário de ver grupos subalternizados em relação ao poder, e discursos nascem em torno delas, como exemplo, o do empoderamento feminino, adjetivo tão acionado quanto problemático, pois é tomado em simetria à hegemonia que deveria se incomodar com seu uso.

O que significa dizer que, ao localizar o reconhecimento no padrão de status, por essa postulação requerida, se torna possível uma averiguação mais detida das formas institucionalizadas de poder, de modos de atuação sobre a exclusão do outro. O modelo de identidade partilha de um que justifica o todo, promovendo um olhar essencialista sobre os grupos. A moralidade justificada como essência das formas de apreensão do outro é uma prática bastante comum de grupos hegemônicos e conservadores ao se colocarem diante da alteridade do escravo para fazer uso da figura hegeliana. Portanto, o olhar essencialista é uma inferência crítica que necessita ser tensionada, como apresenta essa proposta. Nesse teor, de acordo com Nancy Fraser, encontra-se uma grande vantagem da adoção do modelo de status, pois

diferentemente do modelo da identidade, ele entende o reconhecimento de uma forma em que esse não é colocado no campo da ética. Concebendo o reconhecimento como uma questão de igualdade de status, definido então como paridade participativa, ele fornece uma abordagem deontológica do reconhecimento. Sendo assim, ele libera a força normativa das reivindicações por reconhecimento da dependência direta a um específico e substantivo horizonte de valor (FRASER, 2007: 110).

${ }^{2}$ Em outro texto de Nancy Fraser esse contraponto a Honneth é elaborado de forma mais expandida. Esse debate entre os autores pode ser melhor compreendido em Fraser e Honneth (2003).

\footnotetext{
${ }^{3}$ Apenas como ponto a ser trazido ao debate, podemos lembrar que essa condição de uma boa vida, como aposta Axel Honneth, é também bastante frequente da crítica aos produtos audiovisuais que estamos aqui a pôr em questão. Visibilidade e representação idealizadas de grupos minoritários aparecem com frequência como uma forma de se colocar, analiticamente, diante de objetos que localizam os sujeitos em torno dessas implicações. Buscamos, por fim, trazer uma outra maneira de tecer a crítica.
}

Essa ponderação por ela apresentada contrapõe uma ideia já posta por autores como Axel Honneth, da mesma tradição crítica, que preferem entender o reconhecimento como condição de uma boa vida². Essa condição implica aos discursos um ato contínuo da positivação das identidades, como forma de mediações sociais $^{3}$. Mas a dúvida de Fraser permanece ao nos questionar, nas entrelinhas, sobre o sujeito que está fora da cena social. Para Honneth, essa ponderação se trata de um problema de "auto-identidade danificada" (FRASER, 2007: 111).

\section{A essa ponderação, diz Fraser:}

a alguns indivíduos e grupos seja negada a condição de parceiros integrais na interação social, simplesmente em virtude de padrões institucionalizados de valoração cultural, de cujas construções eles não participaram em condições de igualdade, e os quais depreciam as suas características distintivas ou as características distintivas que lhes são atribuídas. Deve-se dizer, então, que o não reconhecimento é errado porque constitui uma forma de subordinação institucionalizada (Ibid.: 112).

Se abre, a partir dessa afirmação de Fraser, um pensamento que pode ser reelaborado nos debates apresentados mais contemporaneamente a respeito dos processos audiovisuais, em seus pontos de produção, recepção e discursivos. E essa é uma contribuição que consideramos importante aos debates acadêmicos e não acadêmicos do audiovisual. Compreende-se que quando o reconhecimento 
se calca no plano ético obscurece uma dimensão não aparente, pois acaba por tomar parte por um todo. Assim, pode-se afirmar que debates que levam o reconhecimento do outro sem uma dimensão complexa, política, apenas na garantia de uma estima no plano cultural, estão sujeitas à lógica excludente da invisibilização de outras agências e sujeitos presentes na cena social. Dessa condição decorrem modos como os que psicologizam o sujeito em meio às relações, Ihe oprimindo por um eventual dano social que ele carrega, já que, "quando o não reconhecimento é identificado com distorções internas na estrutura da autoconsciência do oprimido, basta apenas um pequeno passo para culpar a vítima" (Ibid.: 113). Ainda, segundo a filósofa, pode também naturalizar as formas de estima, classificando-as como direito universal no âmbito social: "Essa visão é flagrantemente insustentável porque torna a noção de estima carente de sentido" (Ibid.: 114).

São todos apontamentos, segundo se percebe, para uma formulação crítica também do fazer dos observadores de produtos midiáticos e audiovisuais. Não nos parece possível, ao menos neste momento, dissociar certa lógica em reorganização no âmbito da sociedade, como aponta Fraser em sua crítica social, dos modos de mediação e apropriação dos objetos que circulam entre os sujeitos. Para retomar algo já trazido neste texto, não nos parece possível mais dissociar a mediação e a vida social, ou seja, há sempre um modo de vida implicado às mediações. Essa visada nos permite compreender determinados ruídos que se apresentam, com caráter fascista, como o ódio em torno da arte contemporânea e produtos culturais diversos. Acredita-se que traçar um novo olhar sobre esses processos faz abrir outro debate que, ao contrário do que se realiza mais atualmente, não oculta o poder e nem as suas formas de atuação por meio dos discursos.

Nancy Fraser debate outras questões em seu texto que se estende em explicações mais elaboradas dos conceitos trazidos por ela e exemplificações da proposta acolhida, por isso indica-se a leitura do texto na íntegra, até pela densidade do debate proposto. O que nos restaria afirmar é que, ao aproximar uma nova proposta da tradição crítica, como se observa em Fraser, aos objetos da comunicação e, precisamente nesse caso, do audiovisual, não se está fazendo nada além do que já foi feito em outros tempos. Sempre foi uma característica da tradição crítica se ligar aos objetos da arte e, a partir do século $X X$, ao que ficou nomeado, entre outras formas, da cultura de massa ou indústria cultural. O que notamos como um certo esgotamento de premissas anteriores não destituiria a crítica social hoje, nem mesmo a sua tradição e seus modos de se colocar, como visto em Fraser e Judith Butler - apenas para citarmos duas filósofas desse debate. O que nos permite também especular, e nada além disso, que a teoria crítica é um movimento de dobra do seu próprio tempo, ou seja, ela é uma volta em si mesma do presente. Por isso pode haver uma distorção entre determinados apontamentos elaborados por Marcuse e Adorno com o que se nota hoje e seja, da mesma forma, necessária uma reatualização dessas bases ainda que elas próprias voltem a ser usadas na crítica cultural e dos objetos. Por exemplo, não é incomum encontrarmos utilização de excertos adornianos que o relativizam, propondo uma reinscrição do filósofo no contemporâneo. O que podemos considerar bastante salutar ao debate e uma afirmativa à tradição histórica da crítica ser sempre algo do momento, uma dobra do presente.

Como a teoria crítica sempre se ocupou do campo estético, entendemos haver uma pactuação possível entre sua proposta e a crítica aos objetos da comunicação e do audiovisual. A filósofa, ao deslocar o reconhecimento do espaço ético à moral, não permanece aí com ele, ainda que proponha um alargamento do conceito de justiça. Dessa forma, retorna à ética para provocar novas questões a esse campo e ao conceito de reconhecimento em construção. Com isso podemos nos aproximar de duas condições trazidas ao longo deste texto: se há reconhecimento sem ética e qual a ética implicada na mediação. 


\section{A ética e o estético}

A questão da ética é quase sempre acionada quando está em debate a alteridade, a condição do outro em causa. Isso num contexto social mais amplo ou mesmo nas discussões mais detidas dos embates reais no âmbito da política, mas não apenas nesses modos de percepção e atuação. Se aproximarmos à discussão central deste texto, parece também ser uma demanda da crítica da mediação a formulação ética, que aposta na positivação das identidades e dos predicados que identificam um determinado grupo. Porém, como já apresentado, ao apressarse na avaliação ética, os sentidos de paridade e de multiplicidade se perdem na mediação e na crítica, afirmando-se, de algum modo, haver idealizações no campo da representação.

Outro ponto que aparece no debate diz respeito ao que Serelle anunciou como uma cumplicidade ideológica com as forças hegemônicas. Reconhecendo, igualmente, que ideologia sempre foi um conceito associado à hegemonia. Aqui se configura uma crítica feita por Silverstone, trazida por Márcio Serelle, sobre os meios de comunicação e que estendemos aos operadores da crítica da comunicação, dos analistas dos objetos da mídia e do audiovisual. Se a mediação está intimamente associada à vida, não havendo mais a diferenciação tão clara entre o representado e o real, como podemos não nos colocar diante do objeto como cúmplices de um poder operante na hegemonia? Em outras palavras, como fazer a crítica à ideologia em suas formas materializadas?

Pretendo discutir que há questões profundamente éticas e morais a ser abordadas no confronto com a mediação da vida cotidiana. Pretendo também argumentar que, na medida em que as características contumazes de representação da mídia contemporânea permanecem, em sua maior parte, incontestadas, aqueles que as recebem e as aceitam não são meros prisioneiros de uma ideologia dominante nem inocentes em um mundo de falsa consciência: eles são, na verdade, participantes voluntários, isto é, cúmplices, ou mesmo engajados ativamente, isto é, acomunados com uma cultura mediada que falha na sua promessa de comunicação e conexão, com consequências duradouras, poderosas e profundamente negativas para nossa condição humana (SILVERSTONE, 2002: 762).

${ }^{4}$ Vale relembrar que o sentido do estético aqui trazido faz referência, em grande medida, ao alargamento do conceito que Jacques Rancière realizou ao associá-lo à Política. Não convém entrar nesses pressupostos neste momento, apenas a lembrança que a partilha do comum no campo social é uma dupla função, estética e política, e então mais do que afirmar um campo político, se faz necessário dizer também em um regime estético de operação do poder e de sua resistência, sobretudo ao se pensar as imagens e as palavras. cf. Rancière (2005).
Se a aposta de Fraser se coloca como uma formulação aplicável, como entende este texto, parece ser necessário dar um passo atrás e interpretar o reconhecimento como uma formulação deontológica, ou seja, do campo da moral, deixando transparecer uma impossibilidade em localizar a ética ao se ausentar desse lugar anterior. A ética, nessas bases críticas, se apresenta condicionada pelo estético ${ }^{4}$, como forma da imagem, do audiovisual e da crítica. Se o texto adota que a ética se estende ao estético e nele se completa, e pede a multiplicidade das mediações e a paridade nas relações, pode-se igualmente reivindicar uma condição inversa ao reconhecimento ao retornar à ética. De acordo com Serelle, Silverstone adota em sua epistemologia da comunicação a adesão de um outro que não seja o mesmo e refaz sua crítica no sentido de haver modos de mediação que buscam emoldurar o outro, inclusive na formulação da crítica de mídia, que subscreve o que o produto apresenta. O que Silverstone almeja, portanto, é a ascensão de uma alteridade radical ou a afirmação de "um outro absoluto, cuja humanidade compartilhamos ainda que esta seja de uma substância realmente diferente" (SERELLE, 2016: 85). A questão da multiplicidade ainda se coloca como fundante na crítica.

Um caminho para equacionar o debate da multiplicidade no campo estético se apresenta como uma condição antipredicativa do reconhecimento, de forma semelhante ao que nos apresenta Vladimir Safatle (2016). A adoção dessa perspectiva se coloca não apenas pela impossibilidade de justificar as demandas no plano ético das identidades, mas também por uma mudança do éthos 
${ }^{5}$ Pode ser melhor apreciada essa mudança no mundo do trabalho ao longo das últimas décadas do século $X X$. cf. Boltanski e Chiapello (2009). social do trabalho ${ }^{5}$ e, por que não dizer, do desejo - se considerarmos as lutas reivindicatórias de grupos minoritários a partir do século $X X$, sobretudo na década de 1970, e que permanecem vivas ainda hoje em outros estágios -, requisitos emergentes em uma extensão da multiplicidade. Complexificando-se, assim, o status de uma formulação universal do proletário reivindicada nos séculos XIX e parte do século XX. Portanto,

como o debate político de então se ordenava a partir da determinação genérica do proletariado, falar de reconhecimento no campo político mostrava-se desnecessário. É apenas com abandono gradativo dessa crença na universalidade concreta da classe proletária que sobe à cena o problema de multiplicidades que precisam ser reconhecidas dessa forma no interior do embate social (SAFATLE, 2016: 224).

Paralelo a isso, vemos nascer no final do século um desmonte ao Estado de bem-estar social em todo mundo, que rebateu até em países em que o capitalismo tardiamente se colocou em suas bases. O que implicou em outras formas de precariedade, e em imensas dificuldades em se afirmar conquistas - o Brasil parece ser um exímio exemplo ao que se coloca no embate entre neoliberalismo e um novo projeto nacional. Se impõem, dessa maneira, mudanças culturais que reivindicam novos olhares ao lugar social do reconhecimento, participando da fruição do pensamento fraseriano que recomenda outras formas e articulação dos conceitos diante das novas demandas do social. É o mesmo desafio da crítica de mídia e do audiovisual ao se colocar diante dos objetos em causa na análise. O nosso interesse maior é pensar em objetos audiovisuais e da mídia que afetam, com suas imagens em profusão, um determinado circuito no social. Que dizem para além do que ele apresenta em sua espessura, ativos em observações numa cultura audiovisual. Porém, localiza-se a crítica em um modo mais expandido de percepção desses objetos e colocando na análise uma função mediadora na geração de um estatuto aos objetos.

Ao voltar à questão do proletário, se faz possível reconhecer certa ineficácia do conceito antes colocado pelos pós-marxistas, como um signo universal da revolução que organizaria trabalhadores de todo o mundo em busca de um comum. Porém, afirmar essa hipótese não significa dizer nem da inabilidade em trabalhar com o conceito de proletário no tempo presente e nem do abandono do sentido do comum. Aliás, a ideia do comum nunca esteve tão presente como em diversos debates e autores que se colocam atualmente. Convém, desse modo, reinserir o conceito de proletário para depois fazer a sua revisão no campo estético e chegar na imagem, ponto nodal de nossa crítica em torno dos objetos audiovisuais tomados a partir de uma cultura audiovisual.

Parece, nesse teor, adequado pensar em um sujeito antipredicativo ou, como também coloca Vladimir Safatle, um sujeito indeterminado socialmente. Se realocarmos no hoje o conceito de proletário pode-se pensar não em uma união genérica dos trabalhadores do mundo tudo, mas em uma formulação do pensamento que não aposta no sectarismo das diferentes posições de sujeitos, ao contrário da identidade que reafirma lugares fixos no laço social e atua em formas de separação e segregação dos sujeitos participantes. O que, apesar de uma luta por reconhecimento das diferenças, também não garante a paridade, como já mencionado por Nancy Fraser. Portanto, uma forma de escapar conceitualmente desse problema ético se coloca em uma nova forma de apreender o proletário, hoje apresentado em uma multiplicidade sem fim das posições de sujeito. Todas em busca de visibilidade no campo social. O debate crítico deve ser em torno das mediações das diferenças, entendendo a crítica também como uma mediação.

Portanto, se algumas formas de reivindicação proletária hoje parecem ter um esgotamento, não se pode afirmar que essa potência deixou de fazer presença, ainda que invisibilizada. Justamente no ponto em que se torna invisível no processo 
de mediação é que podemos reconhecer como uma condição importante a se considerar no regime estético. Pois o proletário

\begin{abstract}
é marcado pela ausência de qualquer expectativa de retorno. Ele é uma heterogeneidade social que simplesmente não pode ser integrada sem que sua condição passiva se transforme em uma atividade revolucionária. Por isso, ao ser desprovido de propriedade, de nacionalidade, de laços com modos de vida tradicionais e de confiança em normatividades sociais estabelecidas, ele pode transformar seu desamparo em força política de transformação radical das formas de vida (Ibid.: 236).
\end{abstract}

A imagem aqui trazida, por sua vez, sempre se coloca como uma forma incapaz de entrar plenamente, ainda que ela sempre esteja presente. Ela pode ser compreendida como uma imagem que insiste, e resiste, por uma espécie de real figurado inalcançável ${ }^{6}$. Ou seja, a imagem análoga ao conceito trazido de proletário seria uma imagem de resistência e de insistência, ora por ser inesperada em sua projeção, indefinível, ora por condensar em sua aparição diversas demandas que dialogam com o corpo político em construção. Seriam, em associação, formas de articulação do desamparo justificada pelo encarar da imagem dos observadores participantes ou não da cena social. Um contrapor-se à imagem da hegemonia, em alguns casos, e uma interferência material de uma imagem que falta. A invisibilidade, nesse sentido, seria a imagem que se ausenta, já que a falta também é uma forma de presença. Por esse motivo, assim como não é possível desarticular a ética da moral em disputa, ela também não pode ser vista sem o estético, ausente do regime que comporta imagens e sujeitos.

Jacques Rancière (2015) nos remonta um detalhe importante que por vezes não aparece ao se colocar criticamente diante da imagem. A priori, nomeia uma crítica da imagem como uma subversão danosa à imagem, uma espécie de iconoclasmo teórico que suporta e justifica uma verdade da imagem. A isso que nomeamos subversão, o filósofo classifica como uma crença marxista "na inversão do mundo invertido" (Ibid.: 191). Ou seja, a forma crítica que se apoia em uma "visão platônica da separação entre o mundo sensível das aparências visíveis e o mundo inteligível, acessível somente pelo exercício dialético" (Ibid.: 192). A partir dessa lógica, a dissociação entre sujeitos dialéticos e imagens alienantes fica mais evidente, porém, a pergunta de uma dissociação entre imagens e sujeitos, como se eles não participassem de um mesmo espaço ético e estético ainda persiste sem afirmativas. Não significa, a bem dizer, que as imagens se sobrepõem aos sujeitos, como uma espécie de obscenidade técnica, porém, no regime de partilha do sensível, imagens e sujeitos estão em constante relação. $\mathrm{E}$ nessa relação apresenta-se o sujeito e a imagem em junção com poucas brechas e separações, mas com espaços de realinhamentos. Se faz necessário reconhecer o esgotamento da imagem revolucionária, assim como do proletário como um signo de inversão genérica do mundo em desconstrução.

Se a crítica das imagens teve seu momento, foi talvez porque a mudança de época, anulando seus poderes, revelou os pressupostos duvidosos que a fundaram, ao tempo mesmo que a fé num futuro de revolução ou de progresso sustentava os empreendimentos e voltava a examinar seus princípios (Ibid.: 193).

Rancière introduz criticamente uma dimensão trazida pelo teórico W. J. T Mitchell (2015), em que afirma haver uma relação conflituosa entre a imagem e o visível, o que poderíamos também afirmar em relação aos sujeitos indeterminados, e que as "falas" das imagens poderiam ser notadas em suas condensações de demandas, sobretudo, e em seus deslocamentos. Aqui se nota uma crítica de Rancière à petrificação da imagem como um signo linguístico estático, imanente em essência. Insistindo na associação entre o reconhecimento de um sujeito 
antipredicativo e a imagem, é como o de encontrar no movimento da imagem o seu lugar de fala, nem sempre compreendido por uma atribuição linguística que busca a essência e a idealidade revolucionária, mas que pode fazer presença ao ser construída sobre ela um estatuto que adere à sua voz. Assim como se busca na teoria social um conceito de reconhecimento que não se prenda à política identitária, ao ideário do signo revolucionário.

O horizonte crítico das imagens e dos sujeitos seria um pós-identitário, o que não permite aprisionar o outro da imagem aos predicados atribuídos a ele e relativizar as forças em operação. Nessa perspectiva lançada, como colocada por Nancy Fraser, não é possível falar em multiplicidade sem o debate ético e moral, sem reconhecer complexidades no campo da cultura. Diante disso, afirma Safatle (2016: 240):

Poderíamos acrescentar uma interpretação dessa situação, afirmando que isso pode significar uma articulação entre liberalismo e multiculturalismo que usa a afirmação da diferença cultural como compensação para a paralisia política em relação aos efeitos sociais das políticas econômicas e liberais.

O que nos auxilia na afirmação de que a crítica da imagem em disposição na cultura audiovisual tem uma dupla constância, seja ela qual destino tiver e com qual objeto trabalha: as identidades e o regime econômico implicado pelo contexto e pela sociabilidade. Ao esquecer de um dos pontos concorre-se para a desarticulação política em jogo. Em outras palavras, a crítica da cultura tem que levar consigo uma crítica à política hegemônica, à lógica do neoliberalismo. $\mathrm{O}$ alargamento do modelo de identidade por uma política do reconhecimento, tal como proposta por Fraser, também localiza no campo das imagens as suas multiplicidades e certa voz subalterna da imagem. Ainda, permite justificar as reponsabilidades implicadas na crítica como mediação dessas multiplicidades.

Por fim, uma dupla junção que permite aos observadores dispostos a ver localizar os movimentos das imagens, de suas proliferações e profanações contra-hegemônicas. Que retire do reconhecimento a necessidade exclusiva de afirmação da identidade e lhe permita também uma abertura aos sentidos em disputa, à multiplicidade dos sujeitos, das imagens e das mediações.

\section{Referências}

BOLTANSKI, L.; CHIAPELLO, E. O novo espírito do capitalismo. São Paulo: WMF Martins Fontes, 2009.

FOSTER, H. O retorno do real. São Paulo: Cosac Naify, 2014.

FRASER, N. Reconhecimento sem ética? Lua Nova, São Paulo, n. 70, p. 101-138, 2007.

FRASER, N; HONNETH, A. Redistribution or recognition? A political-philosophical exchange. New York; London: Verso, 2003.

FOUCAULT, M. Estratégia, poder-saber. 3. ed. São Paulo: Forense, 2012. (Coleção Ditos e Escritos, v. 4).

MITCHELL, W. J. T. O que as imagens realmente querem? In: ALLOA, E. (Org.). Pensar a imagem. Belo Horizonte: Autêntica, 2015. p. 165-190.

RANCIÈRE, J. As imagens querem realmente viver? In: ALLOA, E (Org.). Pensar a imagem. Belo Horizonte: Autêntica, 2015. p. 191-204. 
. A partilha do sensível. São Paulo: Editora 34, 2005.

SAFATLE, V. O circuito dos afetos: corpos políticos, desamparo e o fim do indivíduo. 2. ed. Belo Horizonte: Autêntica, 2016.

SERELLE, M. A ética da mediação: aspectos da crítica de mídia em Roger Silverstone. Matrizes, São Paulo, v. 10, n. 2, p. 75-90, 2016.

SILVERSTONE, R. Por que estudar a mídia. São Paulo: Loyola, 2002. 